\title{
Fatal intrathoracic sepsis associated with neck space infection
}

\author{
M ZALTZMAN, J KALLENBACH, M HOCKMAN, RCA MORRISON, M LEWIS, S ZWI \\ From the Departments of Medicine and Otorhinolaryngology, University of the Witwatersrand and \\ Johannesburg Hospital, Johannesburg, South Africa
}

\begin{abstract}
Although infections of the upper respiratory tract are extremely common and generally run an uncomplicated course, they are occasionally fatal. We describe a case in which upper respiratory tract infection was associated with neck space infection leading to extensive intrathoracic sepsis and death.
\end{abstract}

\section{Case report}

A 46-year-old white woman, previously healthy, was admitted to Johannesburg Hospital complaining of a sore throat and hoarseness that had lasted for two days. On admission she also experienced pain on swallowing, shortness of breath, and mild retrosternal chest pain. There was no history of accidental ingestion of a foreign body. The patient had smoked 30 cigarettes a day for many years and had been consuming large amounts of alcohol for four months before admission.

Examination showed her to be febrile $\left(38.5^{\circ} \mathrm{C}\right)$ with poor peripheral perfusion despite a blood pressure of $130 / 100 \mathrm{~mm} \mathrm{Hg}$. The heart rate was 135 beats $/ \mathrm{min}$ and the respiratory rate $40 / \mathrm{min}$. The neck was diffusely swollen with palpable crepitus. There was no inspiratory stridor. The patient was edentulous and, apart from the presence of blood-stained secretion and considerable halitosis, the mouth and postnasal spaces were normal. The pharynx was injected but appeared to be otherwise normal. Areas of ulceration were visible on the margins of the epiglottis and both the epiglottis and the larynx appeared inflamed and oedematous. Apart from clinical evidence of mild obstructive lung disease the remainder of the physical examination gave normal findings.

The chest radiograph showed hyperinflation of the lungs but was otherwise normal. A lateral radiograph of the neck (fig 1) showed the width of the retropharyngeal space at the level of the third cervi-

Address for reprint requests: Dr $M$ Zaltzman, Department of Medicine, Medical School, Hospital Street, Johannesburg 2001, South Africa. cal vertebra to be considerably increased, measuring $20 \mathrm{~mm}$ (normal width $<5 \mathrm{~mm}$ ). The epiglottis, aryepiglottic folds, preglottic soft tissues, and subglottic region appeared to be swollen and extensive gas shadows were visible, extending into the retrolaryngeal and retropharyngeal spaces. The electrocardiogram showed sinus tachycardia, but was otherwise normal.

Other investigations at the time of admission showed: haemoglobin concentration $16.8 \mathrm{~g} / \mathrm{dl}$; white cell count $7.0 \times 10^{9} / 1$; blood urea concentration 11.2 $\mathrm{mmol} / \mathrm{l}(67.2 \mathrm{mg} / 100 \mathrm{ml})$ with normal electrolyte concentrations. Analysis of arterial blood gas taken while the patient was breathing room air showed hypoxia $\left(\mathrm{PO}_{2} 7.92 \mathrm{kPa}\right.$; normal value for Johannesburg (altitude $1760 \mathrm{~m}$ ) $10 \mathrm{kPa}$ ) and metabolic acidosis (pH 7.24, standard bicarbonate $15 \mathrm{mmol}$ $(\mathrm{mEq}) / \mathrm{l})$ ).

A presumptive diagnosis was made of upper respiratory tract infection due to a gas-forming bacterium, with spread into the neck spaces and resultant septicaemia. Treatment was started with penicillin 2 million units 4 hourly, metronidazole $500 \mathrm{mg} 8$ hourly, and gentamicin $80 \mathrm{mg} 8$ hourly, all given intravenously. Five hours after admission the patient's blood pressure became unrecordable. There was no response to fluid administration or to vigorous inotropic treatment and the patient died 16 hours after admission.

A growth of Peptostreptococcus was obtained from blood cultures done at the time of admission. Cultures taken from the mouth and pharynx at this time showed the presence of "normal indigenous bacteria" only, and an Enterobacter species was cultured from the ulcers on the epiglottis.

Postmortem examination showed gangrenous ulceration of the pharynx adjacent to the epiglottis, which was also ulcerated and swollen. Pus was present thoughout the fascial planes surrounding the oesophagus and thyroid gland, extending into the mediastinum, both pleural cavities, and the pericardial cavity. Gram-positive cocci and Gram-negative bacilli were seen in the tissues of the neck (fig 2). 


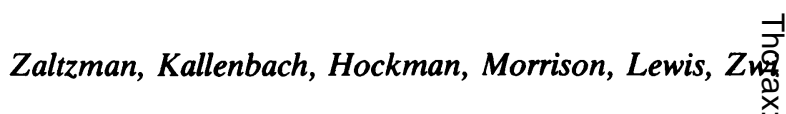

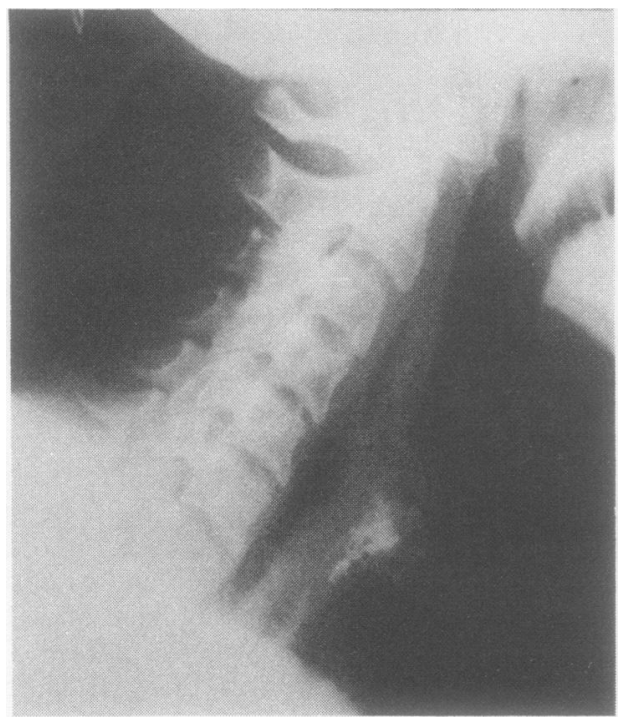

Fig 1 Lateral radiograph of the neck.

\section{Comment}

The anatomy of the cervical fascia has recently been extensively reviewed by Paonessa and Goldstein. ${ }^{1}$ Briefly, the fascia invests the muscles and other structures in the neck, forming tissue planes and potential spaces. The anterior visceral space surrounds the thyroid gland, oesophagus, and trachea and extends from the thyroid cartilage to the anterior mediastinum at the level of the aortic arch. The postvisceral or retropharyngeal space is in direct communication with the anterior viscerai space, and thereby also with the anterior medias? tinum. The "danger space" lies anterior to the pre vertebral fascia extending from the base of the skum to the diaphragm and communicating with both th: posterior mediastinum and the retropharyngea space. These spaces are of considerable clinic/ importance, providing as they do several anatomical routes for the spread of infection originating in the mouth or upper airway through the neck and into the thorax. ${ }^{1}$

The "indigenous flora" of the oropharynx con prises many aerobic and anaerobic bacteria, which are generally of low pathogenicity. ${ }^{23}$ Proliferation of these organisms and tissue invasion may, howeve be caused by an alteration in the normal mucosat barrier, such as occurs with local trauma, or by the lowered redox potential associated with local tissue ischaemia. ${ }^{3}$ The infections which result tend to be polymicrobial, both aerobic and anaerobic bacter being isolated; the commonest organisms found a a peptostreptococci, peptococci, bacteroides, fusobac teria and aerobic streptococci. ${ }^{34}$

Spread of these polymicrobial infections into the neck spaces is known to result in the entity of "synergistic necrotising fasciitis,"5 which almost ce? tainly was present in our case. Further spread in the thorax causes considerable morbidity and hasaa high mortality rate ${ }^{35}$ In addition to mediastinitis, pleurisy, and pericarditis there may be upper airway obstruction, pneumonia due to rupture into the tracheobronchial tree, erosion of vessels, and septic thrombophlebitis, especially of the jugular vein. ${ }^{6} \frac{F}{0}$

Despite the finding in the blood culture of only
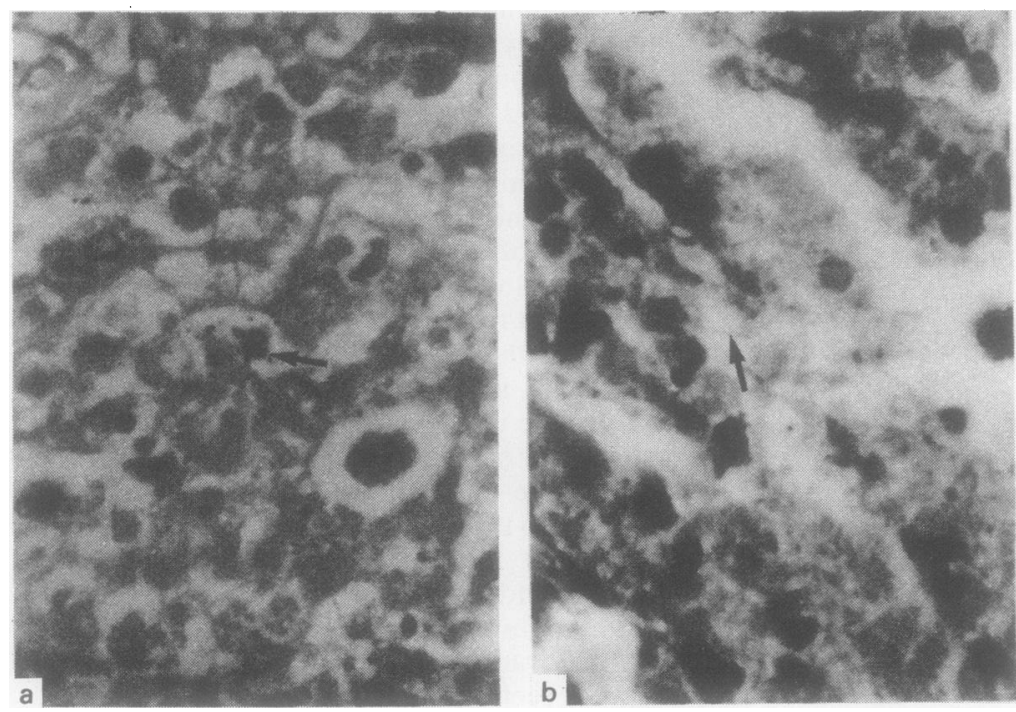

Fig 2 Micrograph of pus from neck taken at necropsy showing (a) Gram-positive cocci; (b) Gram-negative bacilli (arrows indicate organisms). ( $\times 62$

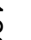


the Gram-positive anaerobic peptostreptococcus, the polymicrobial nature of these infections makes it unlikely that the septicaemia in our case was due to this organism alone. This is further borne out by the growth of Enterobacter sp from the epiglottis and the finding of both Gram-positive cocci and Gramnegative bacilli in the neck at necropsy.

The serious nature of these infections makes it imperative that high doses of intravenous antibiotics are started without delay. While penicillin (in a dosage of 2 million units 2-4 hourly for life-threatening infections) is effective against most of the oropharyngeal flora, metronidazole $(500 \mathrm{mg} 8$ hourly) provides a valuable adjunct to treatment and may be essential if bacteroides are present. Gentamicin provides broad-spectrum cover against a variety of Gram-positive and Gram-negative organisms and should be used in combination with penicillin and metronidazole in serious infections.

It has been suggested that in addition to adequate antibiotic treatment early surgical drainage of both the space primarily affected and all spaces to which the infection has spread, together with wide excision of necrotic tissue, is essential. ${ }^{35}$ Adequate treatment depends on the physicians' awareness that neck sepsis may result in intrathoracic infection. The optimal time for surgery may be difficult to determine, posing a considerable clinical challenge. Despite the rapidly fatal course in our patient, possibly early surgery could have prevented her death.

\section{References}

1 Paonessa DF, Goldstein JC. Anatomy and physiology of head and neck infections (with emphasis on the fascia of the face and neck). Otolaryngol Clin $\mathrm{N}$ Am 1976;9:561-80.

2 Carpenter JL, Artenstein MS. Use of diagnostic microbiologic facilities in the diagnosis of head and neck infections. Otolaryngol Clin N Am 1976;9:611-29.

3 Chow AW, Roser SM, Brady FA. Orofacial odontogenic infections of the head and neck. Ann Intern Med 1978;88:392-402.

4 Bartlett JG, Gorbach SL. Anaerobic infections of the head and neck. Otolaryngol Clin N Am 1976;9:65578.

5 Wills PI, Vernon RP. Complications of space infections of the head and neck. Laryngoscope 1981;91:1129 36.

- Levitt GW. Cervical fascia and deep neck infections. Otolaryngol Clin N Am 1976;9:703-16. 